\title{
Experimental Analysis of Oil Flooded R410A Scroll Compressor
}

Sugirdhalakshmi Ramaraj*, Bin Yang, James E. Braun, Eckhard A. Groll, W.Travis Horton

Ray W. Herrick Laboratories, School of Mechanical Engineering, Purdue University, 177 S. Russell Street, West Lafayette, IN 47907-2099, USA.

E-mail addresses: sramaraj@purdue.edu (Sugirdhalakshmi Ramaraj), yang62@purdue.edu (Bin Yang), jbraun@purdue.edu (James E. Braun), groll@purdue.edu (Eckhard A. Groll), wthorton@purdue.edu (W. Travis Horton)

${ }^{*}$ Corresponding author. Tel.: +1- 3175259882

\begin{abstract}
Approaching quasi-isothermal compression is possible by flooding the refrigerant vapor stream with a liquid that has high specific heat to absorb some heat of compression. To evaluate the benefits of liquid flooded compression, an R410A scroll compressor was tested over a wide range of operating conditions while flooding POE oil into the compression chamber using a hot-gas bypass test stand. The experimental results indicate that oil flooded compression leads to an increase in refrigerant mass flow rate and a decrease in compressor discharge temperature. Also, every operating condition has a maximum limit of possible oil injection, which depends on the system pressure ratio and the dimensions of the injection and discharge ports. By fitting the experimental data, a performance map for the compressor with oil flooding is developed using a semi-empirical model. This map can be used to assess the benefits of the oil flooding technology for various conditions employed in other applications.
\end{abstract}

Keywords: Flooded Compression, Oil Injection, Compressor Efficiency, Refrigeration

\section{NOMENCLATURE}

$\begin{array}{lll}\text { SYMBOL } & \text { UNITS } & \text { DESCRIPTION } \\ C & & \text { Coefficient } \\ f & \mathrm{~s}^{-1} & \text { Frequency } \\ h & \mathrm{~kJ} \mathrm{~kg}^{-1} & \text { Specific enthalpy } \\ \dot{m} & \mathrm{~kg} \mathrm{~s}^{-1} & \text { Mass flow rate } \\ \dot{m}_{\text {total }} & \mathrm{kg} \mathrm{s}^{-1} & \text { Total mass flow rate of oil and refrigerant }\end{array}$




\begin{tabular}{|c|c|c|}
\hline $\mathrm{n}$ & - & Polytropic exponent \\
\hline$P$ & kPa (abs) & Pressure \\
\hline$s$ & $\mathrm{~kJ} \mathrm{~kg}^{-1} \mathrm{~K}^{-1}$ & Specific entropy \\
\hline$S$ & - & Slip ratio \\
\hline$\Delta T_{s h}$ & ${ }^{\circ} \mathrm{C}$ & Compressor suction superheat \\
\hline$T_{1}$ & ${ }^{\circ} \mathrm{C}$ & Refrigerant inlet temperature \\
\hline$T_{11}$ & ${ }^{\circ} \mathrm{C}$ & Oil injection temperature \\
\hline$T_{\text {cond }}$ & ${ }^{\circ} \mathrm{C}$ & Condensation temperature \\
\hline$T_{\text {evap }}$ & ${ }^{\circ} \mathrm{C}$ & Evaporation temperature \\
\hline$T$ & $\mathrm{~K}$ & Temperature \\
\hline$\dot{v}$ & $\mathrm{~m}^{3} \mathrm{~s}^{-1}$ & Displacement rate of compressor \\
\hline$v$ & $\mathrm{~m}^{3} \mathrm{~kg}^{-1}$ & Specific volume \\
\hline$V_{d i s p}$ & $\mathrm{~m}^{3}$ & Volumetric displacement \\
\hline$x_{\text {oil }}$ & - & oil mass fraction \\
\hline$\dot{W}_{e l}$ & kW & Electrical Power \\
\hline$\dot{W}_{i s}$ & kW & Isentropic power \\
\hline$Y_{\text {sep }}$ & - & Mass fraction of refrigerant dissolved in oil \\
\hline$\eta_{o, i s}$ & - & Overall isentropic efficiency of compressor \\
\hline$\eta_{v o l}$ & - & Volumetric efficiency of compressor \\
\hline$\rho_{i n}$ & $\mathrm{~kg} \mathrm{~m}^{-3}$ & Inlet density of the refrigerant and oil mixture \\
\hline
\end{tabular}

\section{Subscripts}

SYMBOL

DESCRIPTION

$1,2,2 s, 11$

State points 

$1,2, \ldots, 21$
Coefficients
c
Critical
oil
Liquid oil
m
Mixture of refrigerant and liquid oil
ref
Refrigerant

\section{Introduction}

With global energy consumption constantly increasing, there exists an ongoing need to improve energy efficiency not only at the system level but also at the component level of vapor compression systems. The compressor is the single largest energy consumer in these systems and any improvement in the efficiency of the compressor will lead to a decrease in total energy consumption. One possible approach to improve compressor performance is by flooding oil into the compression chamber to absorb some of the heat of compression of the refrigerant as it undergoes the compression process and thus, lowering the refrigerant discharge temperature, increasing refrigerant density, and lowering specific work. In addition, larger amounts of oil added to the refrigerant stream can help to seal leakage gaps in the compression mechanism and reduce friction. A few researchers have experimentally investigated injecting significant amounts of oil into screw compressors to seal the leakage gaps and also to control the outlet temperature of the compressor (Blaise and Dutto, 1988; Stosic et al., 1990). Sakuda et al. (2001) and Sawai et al. (2009) investigated flooded compression in scroll compressors and found that the compressor efficiency increased for decreasing oil mass fractions. Hiwata et al. (2002) presented experimental results on flooded compression of a $\mathrm{CO}_{2}$ scroll compressor and proposed the optimal oil flooding rate for different state points considered. Hugenroth et al. (2006) extensively studied liquid flooding to implement an Ericsson cooling cycle. In addition, the authors showed experimentally a possible increase in the Coefficient of Performance (COP) of up to $13 \%$ in heating mode and $9 \%$ in cooling mode for the use of oil as a flooding agent in vapor compression systems.

Bell et al. (2011) developed a complete cycle model with compressor flooding and regeneration for vapor compression systems. The results showed that flooded compression with regeneration has a significant impact on system efficiency especially for large temperature lifts. Test results for an oil flooded residential R410A air conditioning compressor (Bell et al., 2013) showed that refrigerant mass flow rate and overall isentropic efficiency of the compressor increases while discharge temperature decreases with increasing oil injection during compression. Since the compressor was designed with a vapor injection port for air-conditioning applications, there was a decrease in efficiency at lower 
evaporating temperatures due to a mismatch between the imposed pressure ratio and the built-in volume ratio of the compressor. Experimental data from most of the work reported in the literature is not exhaustive, and no performance map has been developed for a compressor with oil flooding. The objective of this work is to evaluate the benefits of oil flooding for large temperature lift applications and to develop a performance characteristic map of the compressor with oil flooding based on experimental results.

\section{Experimental Setup}

\subsection{Test Stand}

A modified hot gas bypass test stand with the configuration shown in Figure 1 was used for testing the R410A scroll compressor with oil flooding. This test stand is primarily used to precondition the oil for injection and the refrigerant to the desired thermodynamic specifications at the inlet to the compressor. Test stand modifications include the addition of a primary oil loop and a secondary oil injection loop to the standard hot gas bypass test stand to realize the objective of oil injection. A primary oil separator is used to store and supply oil for maintaining the oil level in the sump of the compressor. A secondary oil separator is used to supply the oil that is injected into the compression chamber at the inlet conditions. The mixture of oil and refrigerant, after being compressed from low pressure to high pressure in the compressor, is then throttled to an intermediate pressure by the discharge valve. Only one separator was used at a time to either supply oil to the compressor sump or for oil injection. For the purpose of oil injection to the compressor, the oil and refrigerant mixture are directed to the secondary oil separator and separated via gravity and also the centrifugal force that pushes oil drops to get trapped in the mesh. Refrigerant vapor exits the top of the separator while oil with some amount of solved refrigerant drains from a dip-tube. The oil-refrigerant mixture is cooled in the oil cooler to the required temperature and throttled through a set of metering valves in order to control the oil injection mass flow rate. The refrigerant vapor exiting the separator is divided into two streams. One stream is throttled by the bypass valve to suction pressure while the other stream is condensed and expanded to the suction pressure by an expansion valve. The resulting gas and liquid streams are then mixed with the bypass stream to reach the suction conditions entering the compressor. The oil levels in the primary oil separator and the secondary oil separator can be visually inspected and controlled. The system works with three electronic expansion valve (EEV) sets including the discharge EEVs controlling the discharge pressure, the bypass EEVs controlling suction pressure and the condenser EEVs controlling the compressor suction superheat. Figure 2 shows a photograph of the test stand used for compressor testing. 


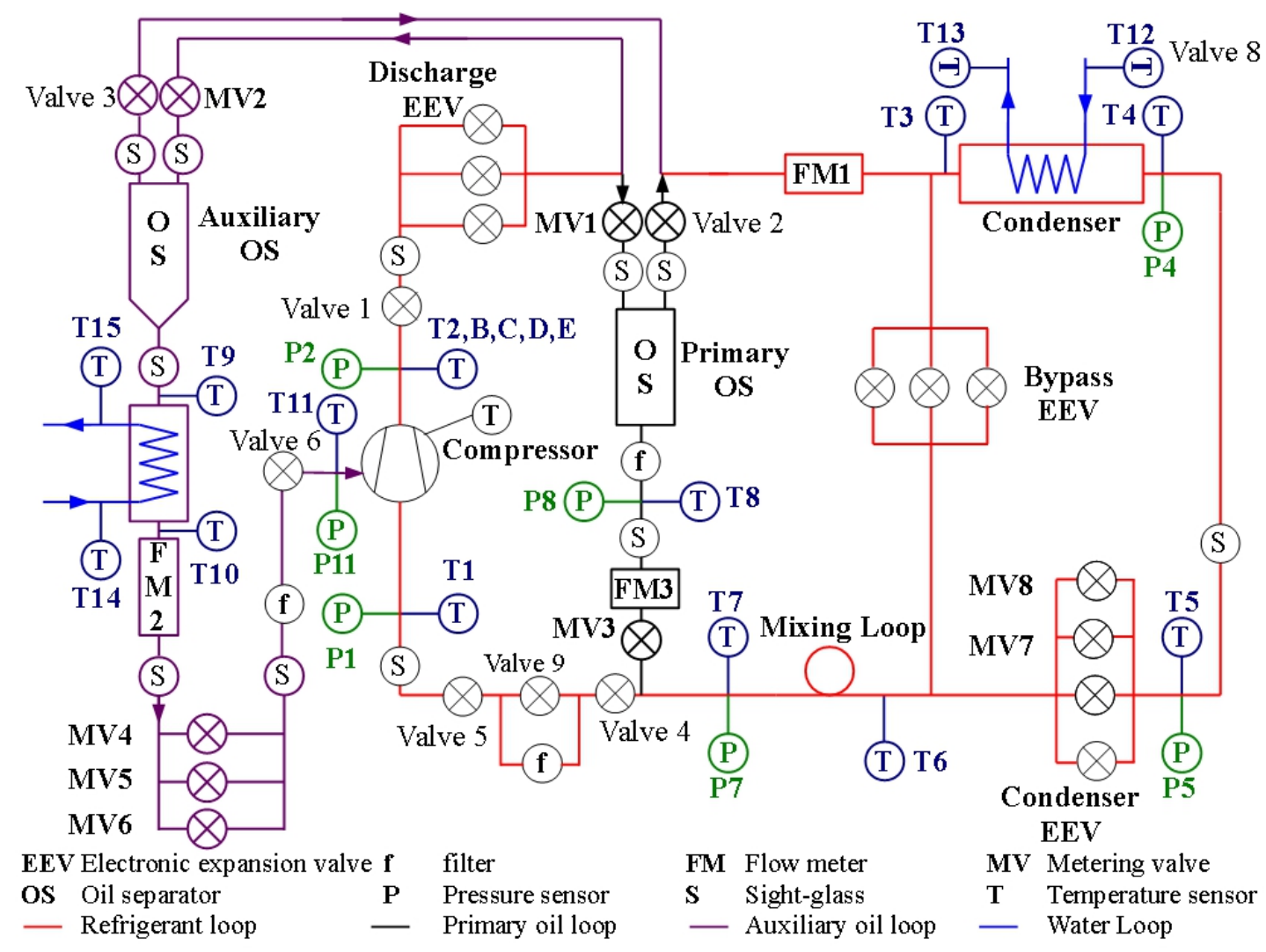

Figure 1. Schematic of hot gas bypass test system modified for oil flooding with instrumentation.

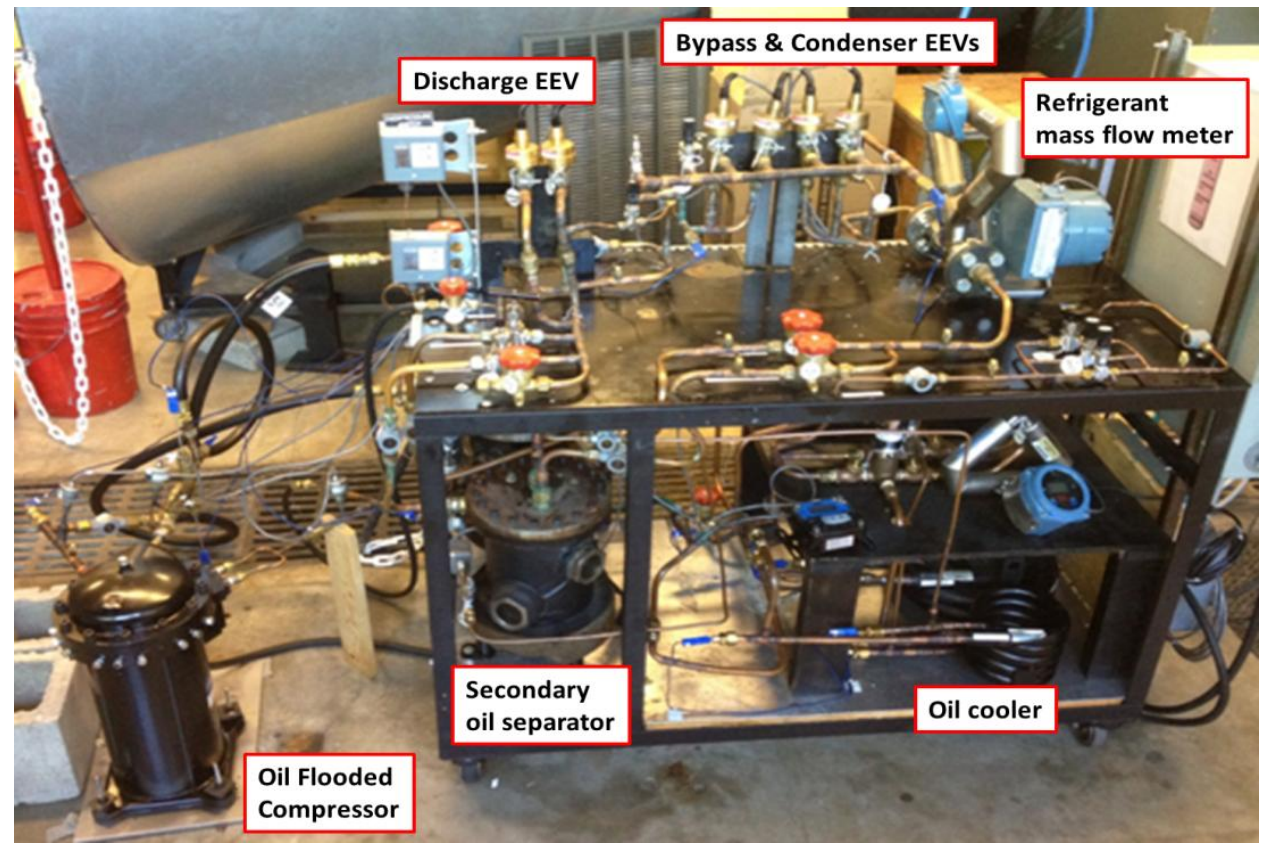

Figure 2. Overview of R410A test stand modified for oil injection. 


\subsection{Compressor}

An oil flooded R410A semi-hermetic scroll compressor with a volumetric displacement of $6.56 \times 10^{-5} \mathrm{~m}^{3}(4$ $\mathrm{in}^{3}$ ) and a volume ratio of 3.29 was utilized for the experimental testing. The compressor has a two-pole motor, and runs on a 200-230V three-phase power supply. The compressor is not equipped with a variable frequency drive and rotates at $3500 \mathrm{rpm}$ under load. The compressor has a side tube connected to the compressor shell to monitor the oil level in the sump. The compressor is designed such that it can handle large flow rates of oil. Figure 3 shows the oil flooded scroll compressor with dual oil injection ports installed in the test stand. The oil is injected into each of the compression chambers just after the compression pockets have been sealed off from the suction chambers. There are some advantages of oil being injected directly into the compression chamber rather than into the suction area. When oil is injected into suction pockets before sealing, the volumetric efficiency may be reduced. When the temperature of the injected oil is higher than the suction gas, the refrigerant gas will be heated, which reduces its density. When oil is separated from refrigerant vapor in the oil separator at discharge condition, some amount of refrigerant vapor is dissolved in the oil at high pressure and temperature. When the pressure of oil is dropped to the suction pressure, the saturation temperature is reduced and some vapor previously dissolved in the oil is released which displaces some suction gas. When the oil is injected into the compression pocket, there is very little impact on the volumetric efficiency. Figure 4 gives the location of the oil injection ports opening into the compression chamber of the R410A scroll compressor. The diameter of the oil injection ports are $2 \mathrm{~mm}$. One oil injection port is located at $111^{\circ}$ and the second oil injection port is at $124^{\circ}$ from the suction seal off. The complete details of the R410A scroll profile are given in Table 1.

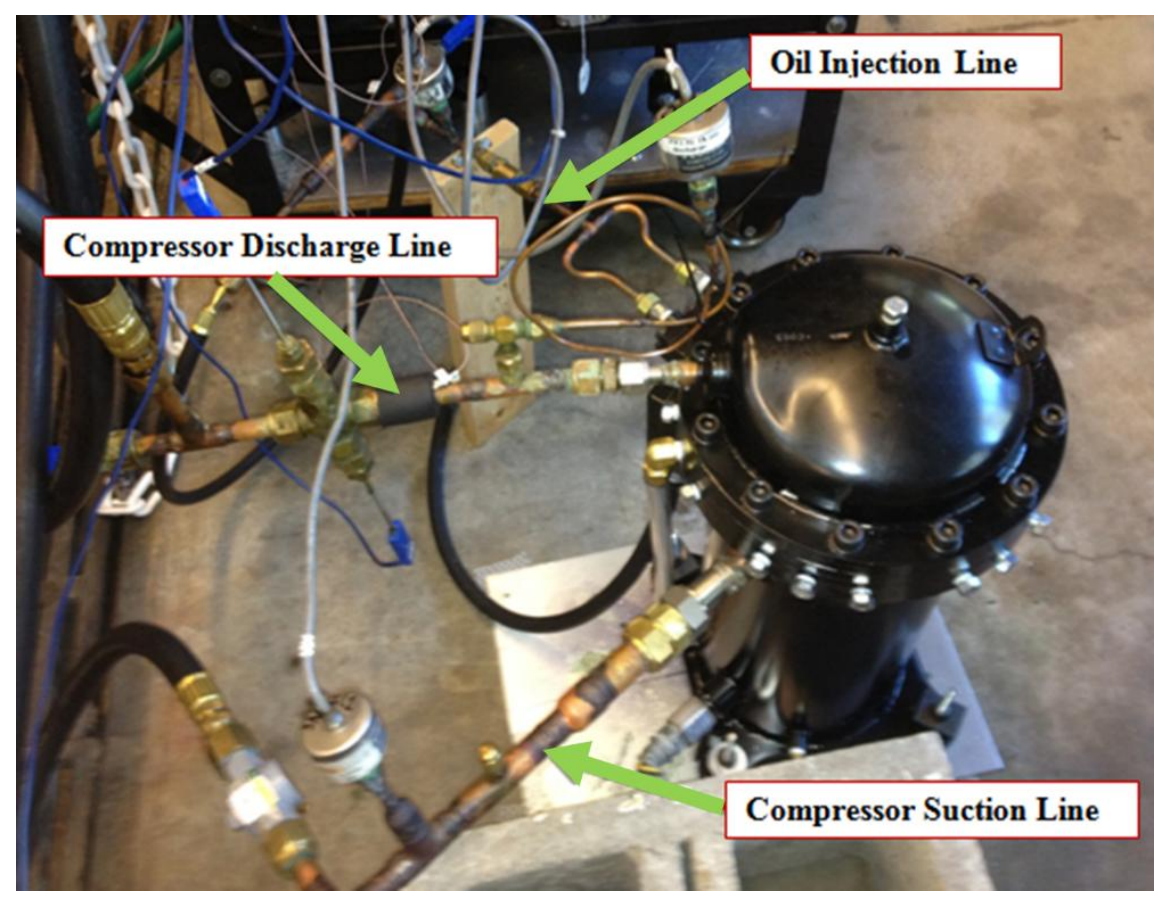




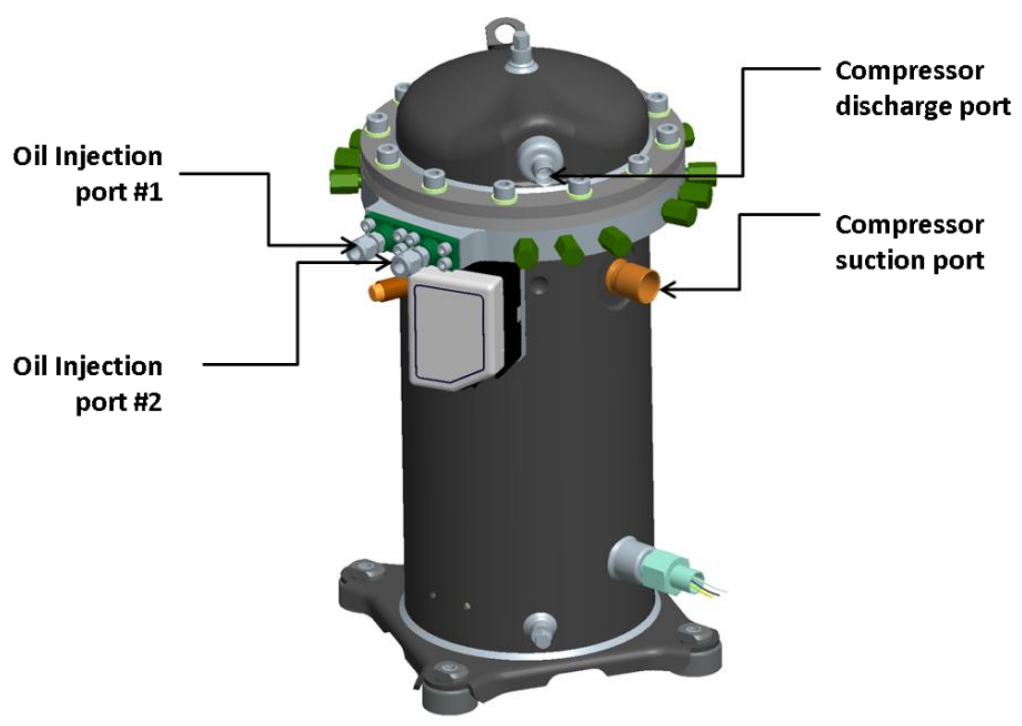

Figure 3. Oil flooded compressor connected to the test stand.

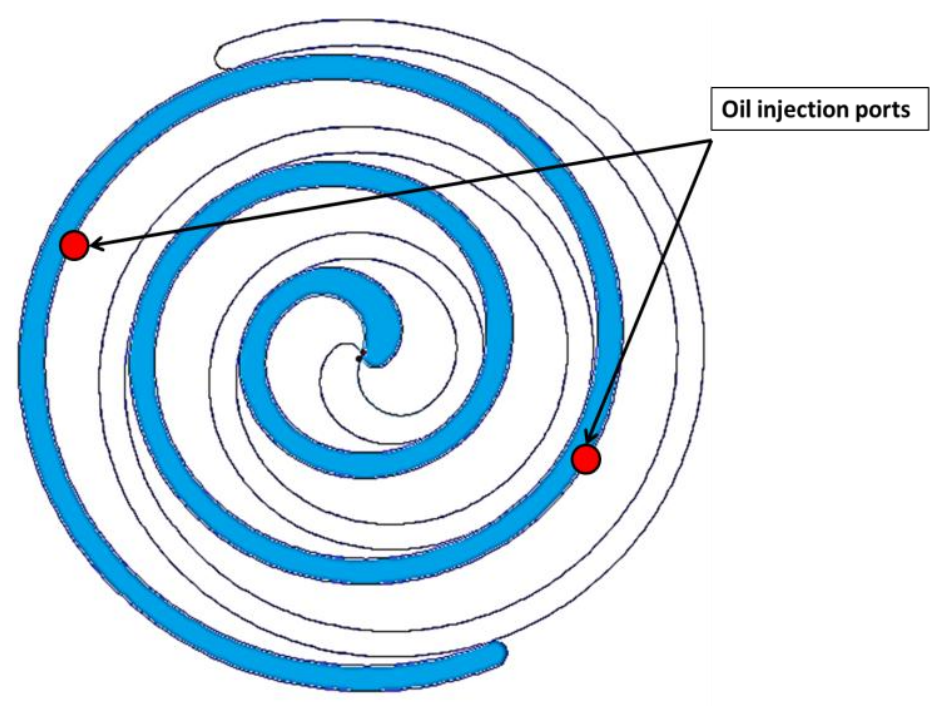

Figure Error! No text of specified style in document.. Location of dual oil injection port in the R410A scroll compressor.

Table 1: Profile of R410A scroll compressor

\begin{tabular}{|l|l|}
\hline Displacement $\left(\mathrm{in}^{3}\right)$ & 4.09 \\
\hline Orbiting radius, $\mathrm{R}_{\mathrm{or}}(\mathrm{mm})$ & 3.99 \\
\hline Generating radius, $\mathrm{R}_{\mathrm{g}}(\mathrm{mm})$ & 2.40 \\
\hline Initial swing radius, $\mathrm{R}_{\mathrm{i}}(\mathrm{mm})$ & 6.87 \\
\hline Wrap involute $($ degree $)$ & 891 \\
\hline Vane Height $(\mathrm{mm})$ & 36.72 \\
\hline Vane thickness $(\mathrm{mm})$ & 3.56 \\
\hline Port Opening (degree) & 90 (after end of involute) \\
\hline Volume Ratio $(-)$ & 3.48 \\
\hline
\end{tabular}




\begin{tabular}{|l|l|}
\hline Port area $\left(\mathrm{mm}^{2}\right)$ & 32.17 \\
\hline
\end{tabular}

\subsection{Other components and measurement devices}

Tube-in-tube counterflow coaxial heat exchangers were used for oil cooling and condensation. A mixture of hot and cold water was supplied to the heat exchangers through thermostatic mixing valves. This allows for a wide range of condensing and oil cooling temperatures.

The refrigerant vapor and the oil are separated by gravity in the separator with the help of internal mesh structures, which employs two layers of spiral mesh, one of which is coarse and the other is fine. The inwardly spiraling path forces the oil to contact the mesh, which causes the oil droplets to coalesce and fall towards the bottom of the separator.

T-Type thermocouples were fully inserted in the flow to measure temperatures at all points. All thermocouples were checked against the freezing point and boiling point of distilled water at ambient pressure and they agreed with the reference temperatures within $0.2^{\circ} \mathrm{C}$. The pressures in the system were measured using pressure transducers with full scale ranges of 0 to 250 psig for the low pressure measurements and 0 to 500 psig for the high pressure measurements both with an accuracy of $3.44 \mathrm{kPa}$. The refrigerant mass flow rate was measured with a Coriolis-effect mass flow meter with accuracy of $0.35 \%$. The oil injection flow rate was measured with a Coriolis-effect mass flow meter with full scale range of $0.6055 \mathrm{~kg} / \mathrm{s}$ and accuracy of $0.05 \%$ for flow rates above $0.0303 \mathrm{~kg} / \mathrm{s}$ and density with an accuracy of $0.2 \mathrm{~kg} / \mathrm{m}^{3}$. The electrical power of the compressor was measured with a watt transducer with an accuracy of $0.2 \%$ of the reading. The condensing and evaporating pressures were dynamically controlled using Proportional-Integral-Derivative (PID) controllers.

\section{Experimental Testing}

Unitary air conditioning and heat pump applications on the market today use R410A as the refrigerant and scroll compressors. Therefore, this work is focused on validating efficiency improvements with oil flooding for R410A scroll compressors. R410A has no ozone depletion potential (ODP) but a global warming potential (GWP) of 1890. The oil employed in this experimental testing is polyolester (POE) oil because of its wide temperature miscibility range, hydrolytic stability, oxidation and chemical stability, and lubricity properties with R410A. The manufacturer recommends 32-3MAF POE oil for scroll compressors when operating with refrigerant R410A and so this was used in the study. For modeling purposes, it is assumed that the refrigerant and oil are in mechanical and thermal equilibrium during the compression process. The solubility of refrigerant in oil is considered only in the oil separator. In the separator, a two-phase mixture of oil and gas enters the oil separator tangentially. The liquid oil is fully separated and passes through a dip tube by gravitational separation. There is no pressure drop, but at high discharge temperature and pressure, some of the refrigerant dissolves in the oil rather than staying in the vapor phase and exits with the liquid oil while the rest of the pure refrigerant vapor exits from the top of the separator. The solubility of R410A in ISO 32 POE oil is determined from the solubility plot shown in Figure 5 (Karnaz, 2012), which is given as a function of temperature and pressure. At a given 
temperature, as the pressure increases, the amount of refrigerant dissolved in the oil increases. For a given pressure, as the temperature increases, the amount of refrigerant dissolved in the oil decreases. Using the measured pressure and temperature in the secondary oil separator, it is therefore possible to estimate the mass fraction of refrigerant dissolved in the oil $\left(Y_{\text {sep }}\right)$.

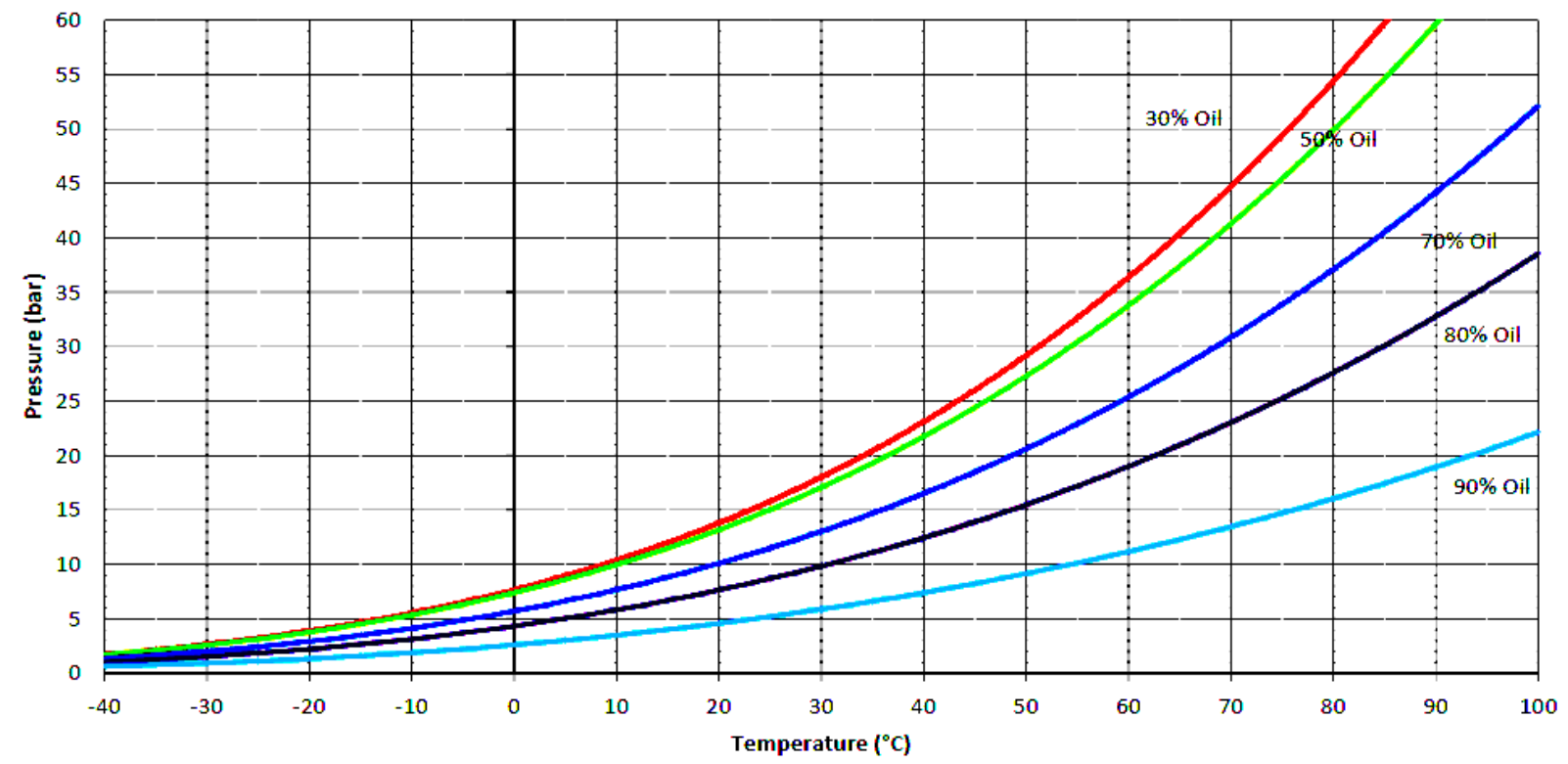

Figure 5. Solubility plot of ISO 32 POE /R410A (Pressure - Temperature diagram).

\subsection{Test Matrix}

To capture the characteristics and performance of the compressor with oil flooding, the compressor was tested by injecting oil at few operating conditions with varying evaporation temperature $\left(T_{\text {evap }}\right)$ and suction superheat $\left(\Delta T_{s h}\right)$. To evaluate the benefits of liquid-flooding for large temperature lifts as experienced in heat pump application, low evaporation temperatures (as low as $-30^{\circ} \mathrm{C}$ ), and a fixed condensation temperature $\left(T_{\text {cond }}\right)$ of $43.3^{\circ} \mathrm{C}$ were implemented during the testing. All operating conditions are shown in Table 2 . For conditions $A$ through $C$, the superheat was varied such that the refrigerant inlet temperature $\left(T_{1}\right)$ and the oil injection temperature $\left(T_{11}\right)$ to the compressor were maintained at $25^{\circ} \mathrm{C}$. This approximates the conditions achieved in a system having a condenser and an oil cooler that rejects heat to the indoor air. However, the full potential of flooding can only be achieved by coupling a regenerator in the oil flooded system to subcool the refrigerant leaving the condenser and to superheat the refrigerant leaving the evaporator. Increased subcooling entering the expansion device leads to reduced throttling losses and increased evaporator refrigerating effect. Heating of the gas prior to the compressor is needed to allow oil injection near the suction of the compressor. Otherwise, the oil injection would need to occur after partial compression in order to achieve the required temperature rise between the evaporator and condenser conditions. The compressor was tested with condition $D$ to study the effects of varying superheat at constant evaporation and condensation temperature. The 
injected oil flow rate was varied for all test combinations to yield a nominal increment of 0.1 in the oil mass fraction until the highest mass fraction was achieved by opening the oil injection valves fully.

During the test runs, it took approximately 1-2 hours to reach a steady state operating condition. This waiting time was caused by the manual control of the superheat with needle valves and by changing water temperatures in the laboratories building water system for the condenser. The changing water temperature made the control of the oil injection temperature challenging.

Table 2. Test matrix for oil flooding.

\begin{tabular}{|c|c|c|c|c|}
\hline Conditions & $T_{\text {evap }}\left[{ }^{\circ} \mathrm{C}\right]$ & $T_{\text {cond }}\left[{ }^{\circ} \mathrm{C}\right]$ & $\Delta T_{\text {sh }}\left[{ }^{\circ} \mathrm{C}\right]$ & $T_{11}\left[{ }^{\circ} \mathrm{C}\right]$ \\
\hline A & -30 & 43.3 & 55 & 25 \\
\hline B & -20 & 43.3 & 45 & 25 \\
\hline C & -10 & 43.3 & 35 & 25 \\
\hline D & -20 & 43.3 & $15-55$ & 25 \\
\hline
\end{tabular}

\subsection{Calculations}

The saturation evaporator and condenser temperatures are found from the measured compressor suction and discharge pressures. Then, from the measured refrigerant inlet temperature $T_{1}$, the compressor inlet superheat is calculated as:

$$
\Delta T_{\text {sh }}=T_{1}-T_{\text {evap }}
$$

The mass flow rate of the injected oil is given as a fraction of the total (refrigerant and oil) mass flow rate through the scroll compressor.

$$
x_{\text {oil }}=\frac{\dot{m}_{\text {oil }}}{\dot{m}_{\text {oil }}+\dot{m}_{\text {ref }}}
$$

From the measured values, the volumetric efficiency and overall isentropic efficiency of the compressor are computed. The volumetric efficiency of the compressor is calculated as follows:

$$
\eta_{v o l}=\frac{\dot{m}_{\text {total }}}{\rho_{\text {in }} \dot{v}}
$$

where,

$$
\begin{aligned}
& \dot{m}_{\text {total }}=\dot{m}_{r e f}+\dot{m}_{\text {oil }} \\
& \dot{v}=V_{\text {disp }} \cdot f \\
& \rho_{\text {in }}=\frac{\left(1-x_{\text {oil }}\right)+S \cdot x_{\text {oil }}}{\left(1-x_{\text {oil }}\right) \cdot v_{r e f}+S \cdot x_{\text {oil }} \cdot v_{\text {oil }}}
\end{aligned}
$$

The inlet mixture density is calculated with slip ratio, $\mathrm{S}=1$ considering a homogeneous equilibrium model for two-phase flow. The power consumption needed for an adiabatic and reversible process operating 
between the actual inlet state $\left(P_{1}, v_{1}\right)$ and the actual outlet pressure $\left(P_{2}\right)$ and with the actual mass flow rate of the oil and refrigerant mixture is given by

$$
\dot{W}_{i s}=\left(\dot{m}_{r e f}+\dot{m}_{\text {oil }}\right)\left(h_{2 s, m}-h_{1, m}\right)
$$

where $T_{2 s, o i l}=T_{2 s, \text { ref }}$ as shown in Figure 6 . The isentropic temperature, $T_{2 s}$ is found by satisfying the equation,

$$
x_{\text {oil }}\left(s_{2 s, \text { oil }}-s_{11, \text { oil }}\right)=\left(1-x_{\text {oil }}\right)\left(s_{1, \text { ref }}-s_{2 s, \text { ref }}\right)
$$

The injected mixture is modeled based on homogeneous oil-refrigerant mixture properties [Bell, 2011]. Enthalpy and entropy at specific state points were calculated with variable oil specific heat capacity. The overall isentropic efficiency of the compressor is

$$
\eta_{o, i s}=\frac{\dot{W}_{i s}}{\dot{W}_{e l}}
$$

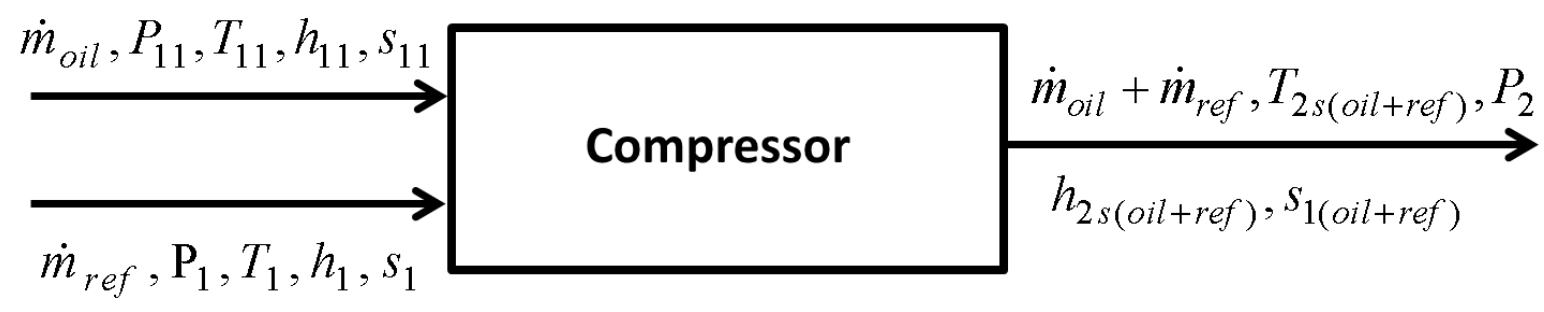

Figure 6. Schematic for isentropic efficiency calculation

\subsection{Experimental Results}

Each point in the test matrix was tested at least twice on different days to demonstrate repeatability in the experimental measurements. The atmospheric pressure was taken into account, since gage pressure transducers were used for the refrigerant-side pressure measurements. Steady state was maintained for almost half an hour for every test condition. At least 5-10 minutes of steady state data was acquired at each state point. The data was then post-processed with a Python script and Engineering Equation Solver (Klein, S.A., 2009) to calculate all parameters not directly measured and the uncertainties in the measurements. Figure 7 shows the performance of the compressor as a function of evaporator saturation temperature, for $43.3^{\circ} \mathrm{C}$ condenser saturation temperature and $25^{\circ} \mathrm{C}$ oil injection temperature. The superheat was varied such that the refrigerant inlet temperature $\left(T_{1}\right)$ is also at $25^{\circ} \mathrm{C}$ as the oil injection temperature $\left(T_{11}\right)$.It can be seen that the discharge temperature is very high when there is no oil flooding (for $x_{\text {oil }}=0$ ). As the oil is injected, the discharge temperature of the compressor decreases monotonically with larger oil mass fractions due to the fact that a fraction of refrigerant's heat of compression is being absorbed by the oil. The discharge temperature is higher for lower evaporator saturation temperatures due to higher pressure ratios across the compressor. In addition, 
the refrigerant mass flow rate tends to increase as the oil injection rate is increased. This increase in refrigerant mass flow rate may be due to better sealing of leakage gaps between higher and lower pressure pockets and also lower temperatures in the suction chamber as a result of lower overall compressor temperatures. It can be observed that the mass flow rate of the refrigerant decreases for higher oil mass fraction due to pressure drop and increasing rotor slip caused by pumping high flow rates of oil. Also, the mass flow rate of refrigerant is higher for increasing evaporation temperature due to higher density. The compressor power consumption is highest with no flooding $\left(x_{\text {oil }}=0\right)$. Oil injection lubricates the rotors, seals the leakage gaps and cools the refrigerant being compressed leading to a reduction in compressor power with oil injection from the no flooding case. In addition, re-expansion of refrigerant in the injection lines with no oil flooding could explain part of the improvement. However, the power increases with oil mass flow rate at higher mass fractions because more incompressible oil has to be pumped along with the refrigerant, which consumes more power. The overall volumetric efficiency of the compressor increases with oil injection rate except at higher oil mass fraction. Also the volumetric efficiency improves with increasing evaporation temperature due to the increase in refrigerant mass flow rate. At an evaporating temperature of $-30^{\circ} \mathrm{C}$ and condensing temperature of $43.3^{\circ} \mathrm{C}$, the volumetric efficiency increases by as much as $14 \%$ for an oil injection mass fraction of 0.5 compared to no oil flooding. The overall isentropic efficiency of the compressor increases with oil injection but decreases for higher oil flow rates. The increase is most likely due to reduced internal leakage and friction, whereas the decrease at higher oil flows is probably due to an increase in pressure drop through suction and discharge pathways. Also, the overall isentropic efficiency improves as the evaporation temperature increases mainly due to increased mass flow rate of refrigerant.

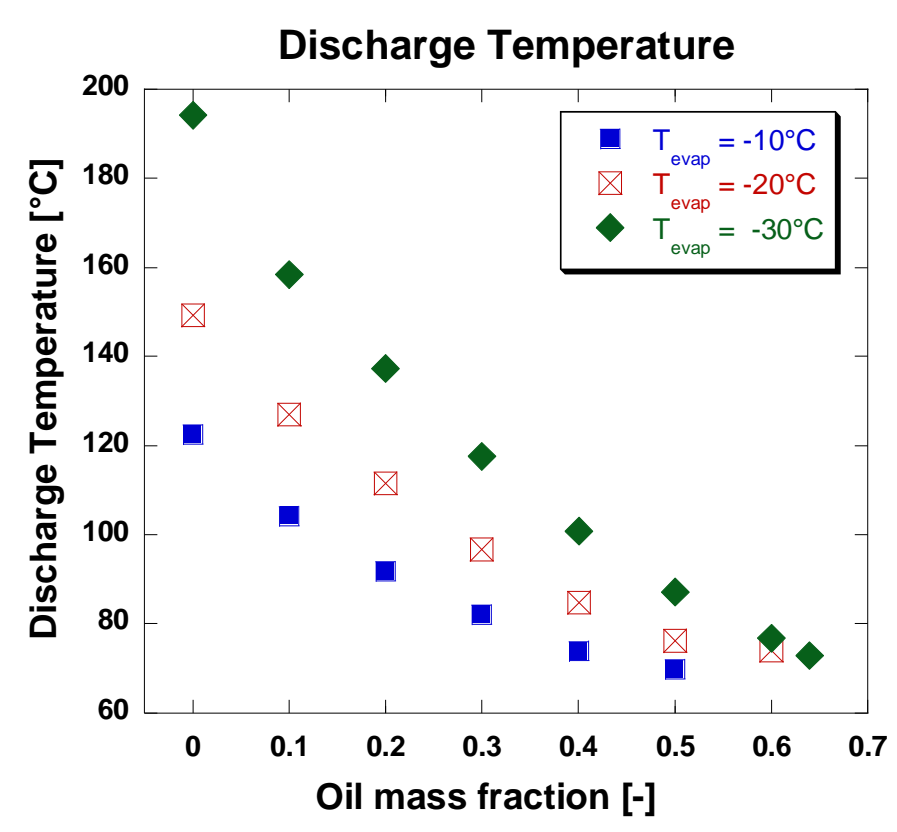

(a) Effect of oil injection on discharge temperature. 


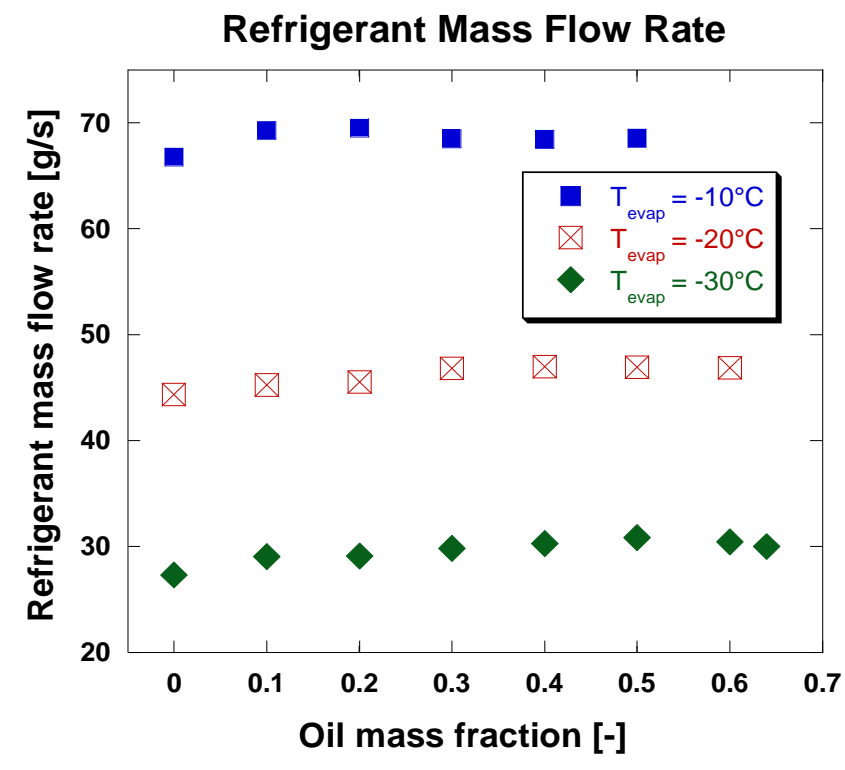

(b) Effect of oil injection on refrigerant mass flow rate.

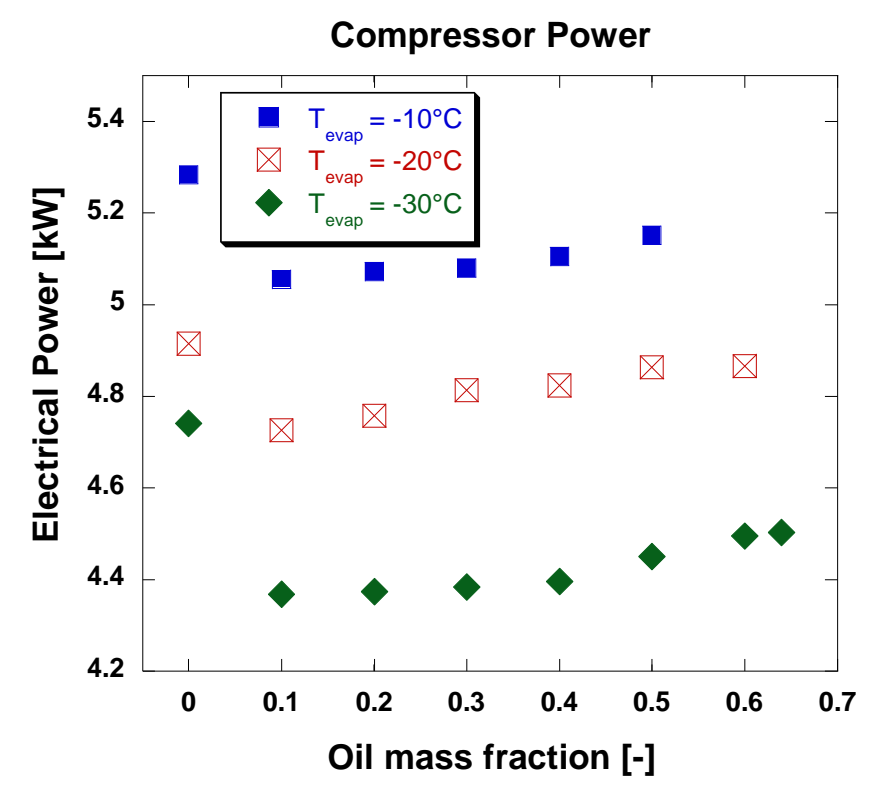

(c) Effect of oil injection on electrical power consumption. 


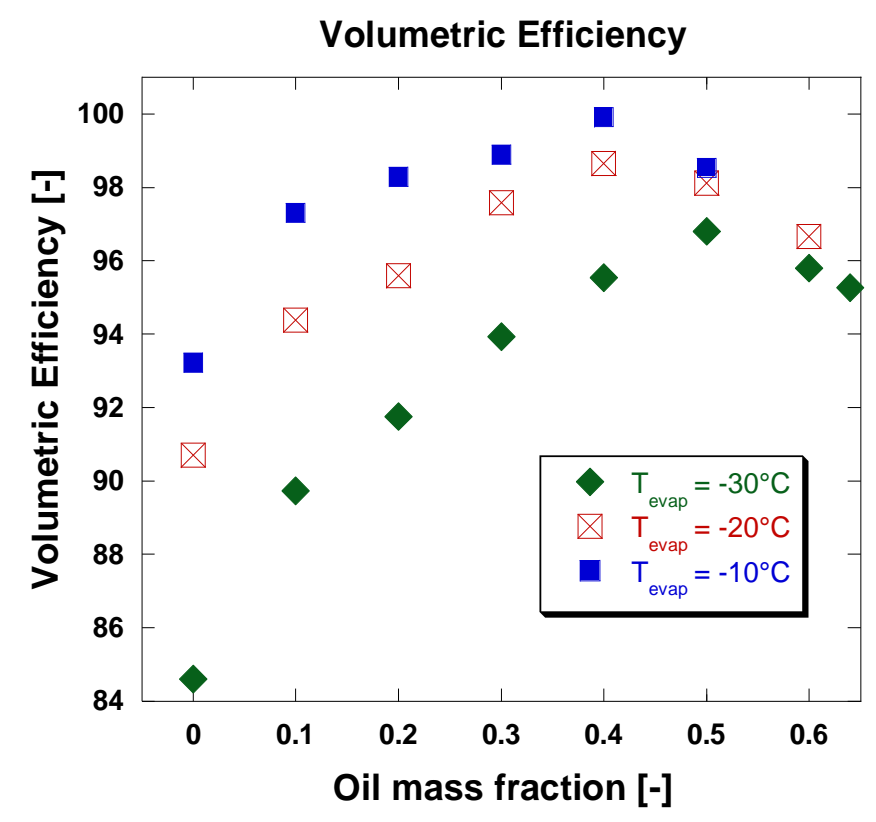

(d) Effect of oil injection on volumetric efficiency.

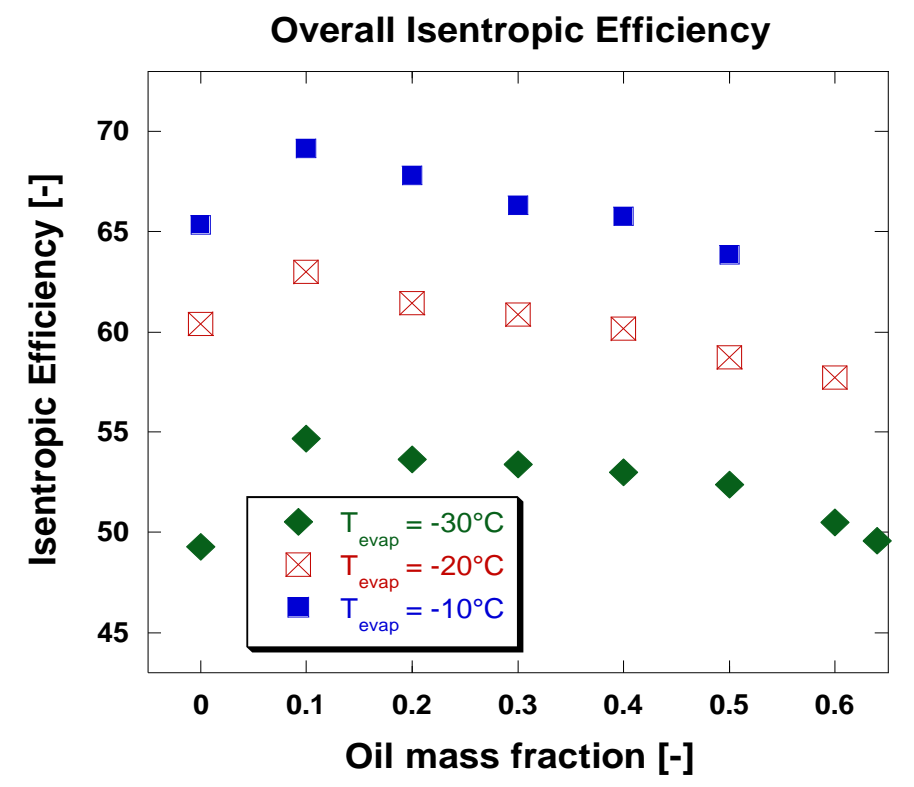

(e) Effect of oil injection on isentropic efficiency.

Figure 7. Performance of compressor for varied $T_{\text {evap }}$ and $T_{\text {cond }}=43.3^{\circ} \mathrm{C}$ with and without oil injection. 
Figure 8 shows the performance of the compressor with oil flooding for varied suction superheat, with $-20^{\circ} \mathrm{C}$ evaporator saturation temperature, $43.3^{\circ} \mathrm{C}$ condenser saturation temperature and $25^{\circ} \mathrm{C}$ oil inlet temperature. It can be observed that the performance of the compressor with increasing oil injection rate for varied superheat is qualitatively similar to the performance with varied evaporation temperature. The discharge temperature of the compressor increases as the suction superheat increases due to the higher suction temperature. As the superheat is increased, the refrigerant mass flow rate decreases due to the decrease in refrigerant density at higher temperature. The compressor power consumption is higher for lower superheat due to higher mass flow rate of refrigerant. There is a large improvement in the volumetric efficiency of the compressor for higher superheat due to the decrease in inlet density of the refrigerant and oil mixture. The overall isentropic efficiency is better when the suction superheat is between $25^{\circ} \mathrm{C}-45^{\circ} \mathrm{C}$. Uncertainties of the experimental measurements are presented in Table 3. Based on error propagation, the maximum uncertainty of volumetric efficiency and isentropic efficiency are $\pm 1 \%$ and $\pm 0.5 \%$, respectively.

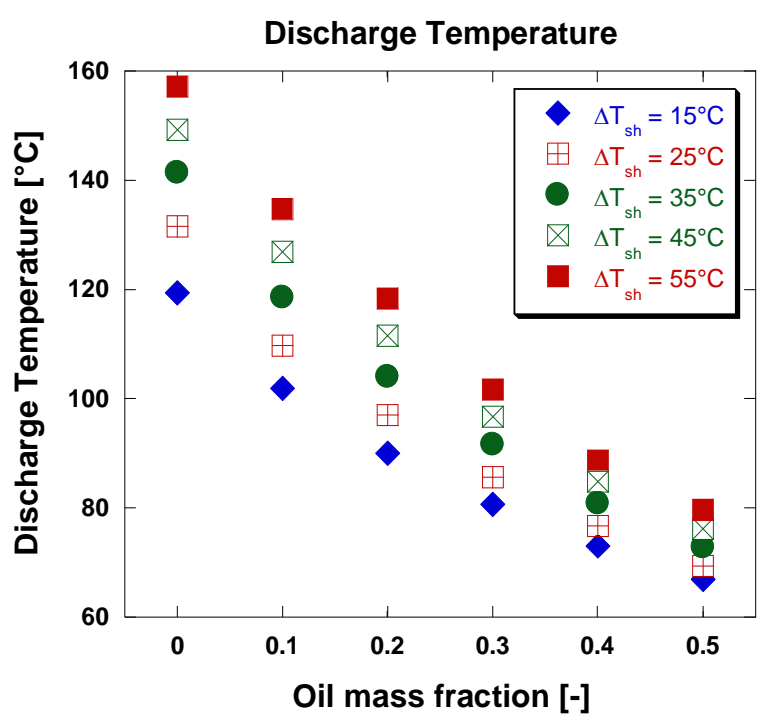

(a) Effect of oil injection on discharge temperature. 


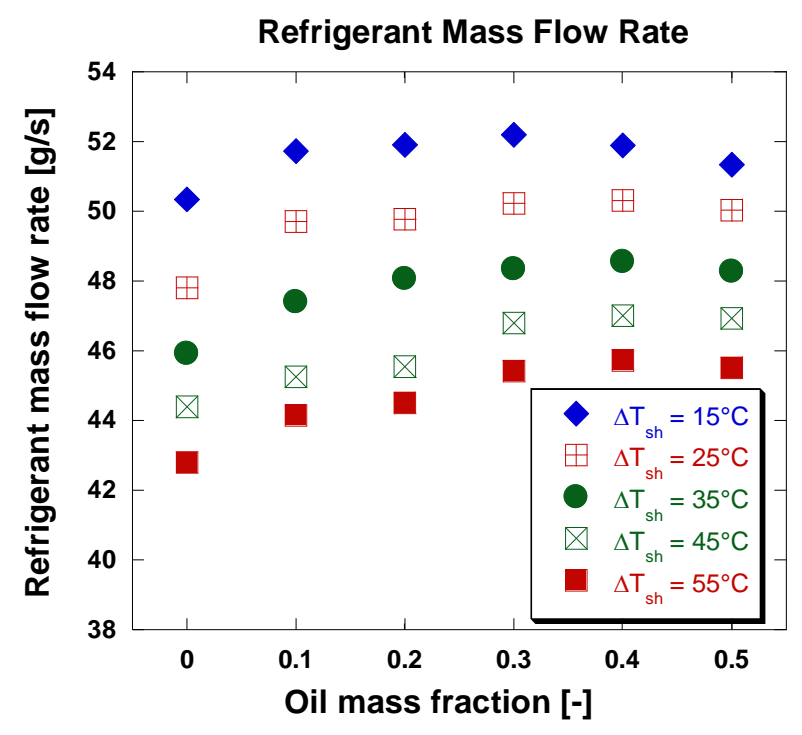

(b) Effect of oil injection on refrigerant mass flow rate.

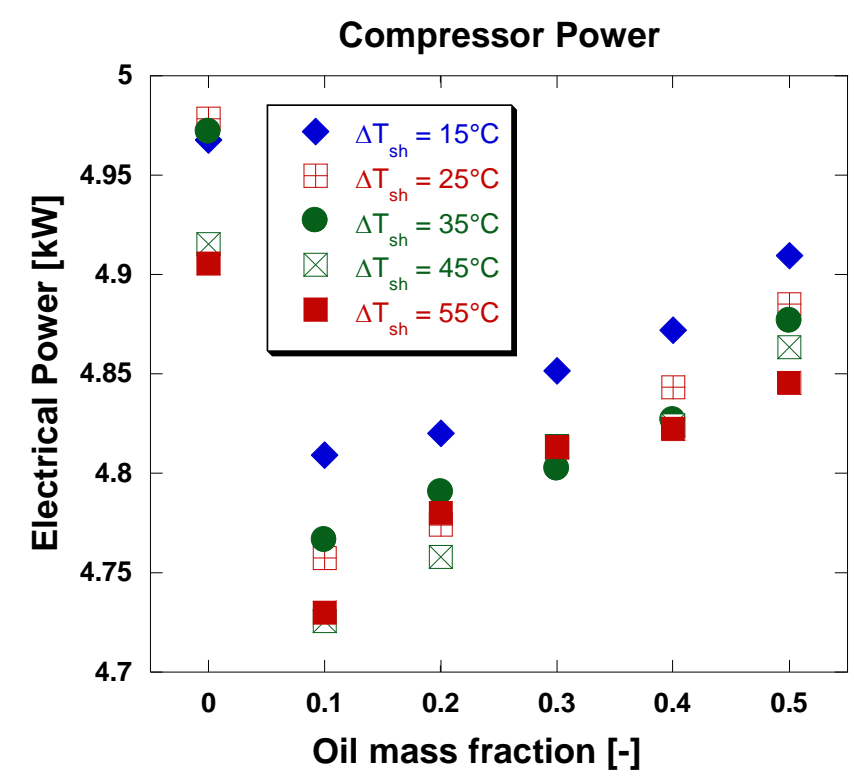

(c) Effect of oil injection on electrical power consumption. 


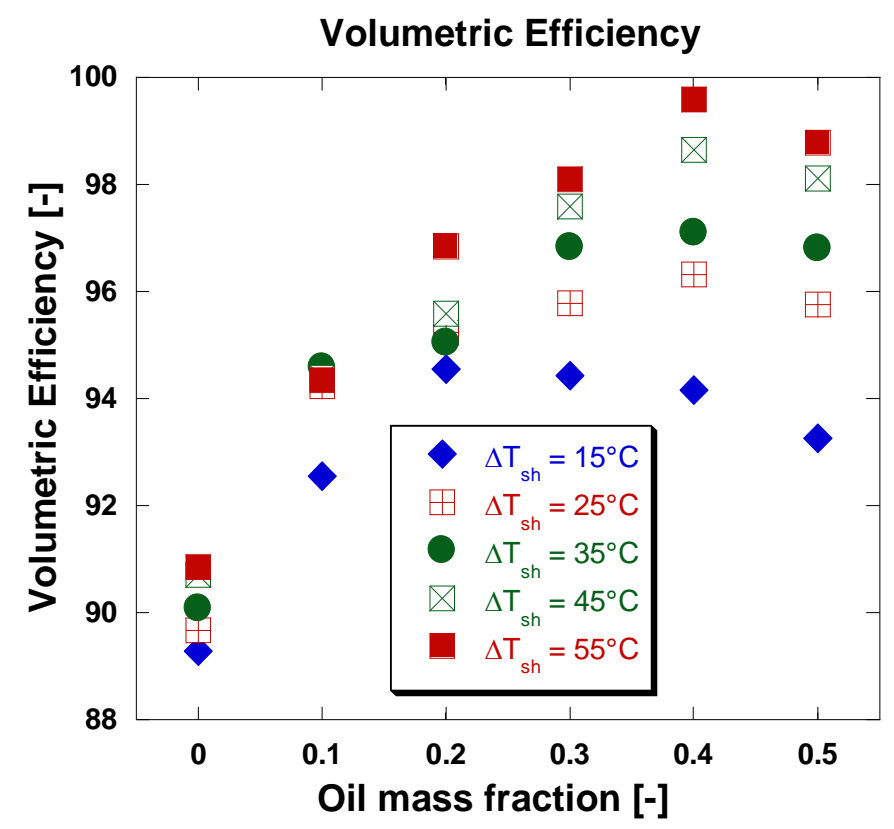

(d) Effect of oil injection on volumetric efficiency.

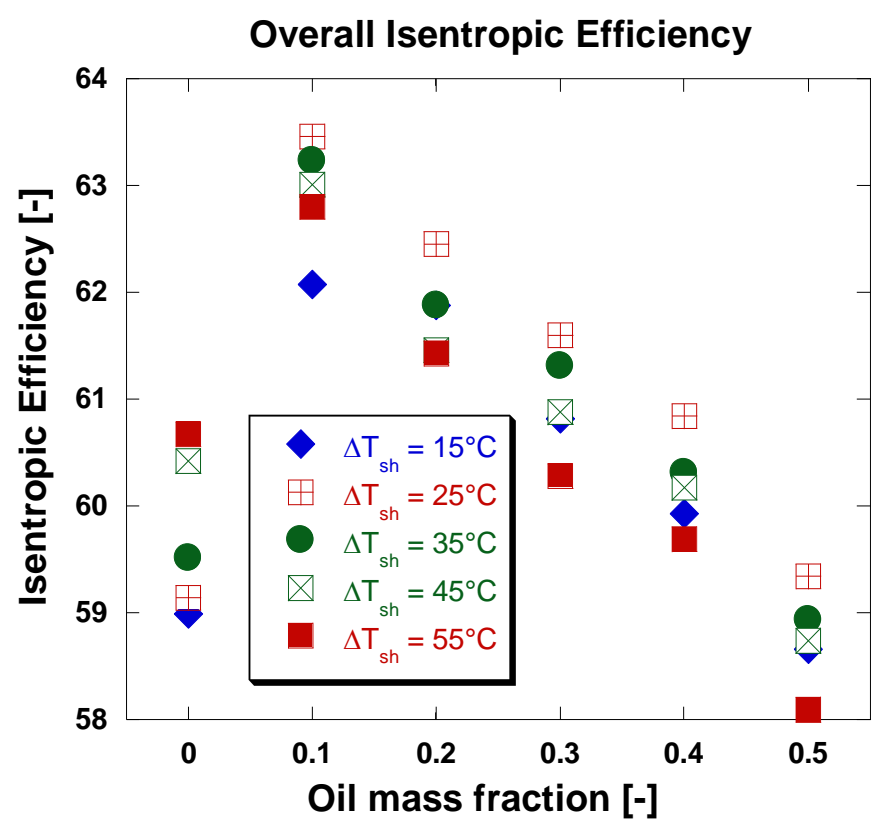

(e) Effect of oil injection on isentropic efficiency.

Figure 8. Performance of compressor for varied superheat $\left(T_{\text {evap }}=-20^{\circ} \mathrm{C}, T_{\text {cond }}=43.3^{\circ} \mathrm{C}, T_{11}=25^{\circ} \mathrm{C}\right)$. 
Table 3. Uncertainty of experimental measurements

\begin{tabular}{|c|c|c|}
\hline Parameter & Symbol & Uncertainty \\
\hline Temperature & $T$ & $\pm 0.2^{\circ} \mathrm{C}$ \\
\hline Pressure & $P$ & $\pm 4 \mathrm{kPa}$ \\
\hline Mass flow rate & $\dot{m}$ & $\pm 0.35 \%$ \\
\hline Compressor Power & $\dot{W}_{e l}$ & $\pm 0.2 \%$ \\
\hline
\end{tabular}

The oil inlet temperature is also an important factor in determining the performance of the compressor with oil flooding. If the oil is not actively cooled prior to injecting it into the compressor, the oil will not be able to provide cooling of the refrigerant during the working process. Cooling the oil always benefits the performance of oil flooded compressor. For the experiment, the $25{ }^{\circ} \mathrm{C}$ oil inlet temperature condition simulates cooling the oil against the sink temperature for an air-to-air heat pump application where the sink temperature is the interior of the building to be heated.

For the no oil flooding test cases, there might have been some re-expansion losses of the gas in the injection lines. During each rotation of the compressor, the gas in the oil injection lines is compressed, and then subsequently re-expands. For every operating condition, there was a maximum amount of oil injected when the valves were fully opened depending on the system pressure ratio and the dimensions of oil discharge port. The maximum amount of oil injected is a function of both the pressure drop in the system and the pressure drop in the compressor.

\section{Correlation based on Experimental Results}

Using the experimental results, a semi-empirical compressor map was developed based on the work done by Cheung and Braun (2012) and Jahnig et al. (2000). Using this compressor map, the compressor total mass flow rate and input power consumption can be determined. The equations used to establish he compressor map are given by Equations 9 to 14 .

$$
\begin{aligned}
& T_{1 m}=\frac{C_{1}\left(1-x_{\text {oil }}\right) T_{\text {ref }, 1}+C_{2} \cdot x_{\text {oil }} \cdot T_{\text {oil }, 1}}{C_{1}\left(1-x_{\text {oil }}\right)+C_{2} \cdot x_{\text {oil }}} \\
& T_{2 m}=\left(C_{3}+C_{4} \cdot x_{\text {oil }}+C_{5} \cdot x_{\text {oil }}{ }^{2}+C_{6} \cdot x_{\text {oil }}{ }^{3}\right) \exp \left[\left(C_{7} \cdot \frac{T_{1 m}}{T_{C}}+C_{8} \cdot \frac{P_{2}}{P_{1}}\right)\left(C_{9} \cdot x_{\text {oil }}+C_{10}\right)\right] \\
& \rho_{m}=\frac{\rho_{\text {oil }} \cdot \rho_{\text {ref }}}{\left(1-x_{\text {oil }}\right) \rho_{\text {oil }}+x_{\text {oil }} \cdot \rho_{\text {ref }}} \\
& n=\ln \left(\frac{P_{2}}{P_{1}}\right) / \ln \left(\frac{\rho_{2 m}}{\rho_{1 m}}\right)
\end{aligned}
$$




$$
\begin{aligned}
& \dot{m}=\rho_{1 m}\left[C_{11}+C_{12}\left(\frac{P_{2}}{P_{1}}\right)^{\frac{1}{n}}+C_{13}\left(P_{2}-P_{1}\right) \cdot\left(C_{14}+C_{15} \cdot x_{\text {oil }}+C_{16} \cdot x_{\text {oil }}{ }^{2}\right)\right] \\
& \dot{W}=\frac{n}{n-1} \cdot \frac{\dot{m}}{\rho_{1 m}}\left(C_{17}+C_{18} \cdot x_{\text {oil }}+C_{19} \cdot x_{\text {oil }}{ }^{2}\right)\left(C_{20} \cdot P_{1}+C_{21}\right)\left[\left(\frac{P_{2}}{P_{1}}\right)^{\frac{n-1}{n}}-1\right]
\end{aligned}
$$

where, $T_{1 m}[K]$ is the fictitious oil-refrigerant mixture temperature at compressor inlet and $T_{2 m}[K]$ is the mixture temperature at compressor outlet. $T_{o i l, 1}$ and $T_{r e f, 1}$ are the injected oil temperature and refrigerant gas temperature before mixing at the compressor inlet in $\mathrm{K}$ respectively. $\mathrm{P}_{1}$ and $\mathrm{P}_{2}$ are the suction and discharge pressure in $\mathrm{kPa}$ (abs) respectively. The values of the coefficients in these equations are given in Table 4. By knowing the oil mass fraction, oil temperature, refrigerant temperature at compressor suction, and both suction and discharge pressures, the compressor mass flow rate, discharge temperature and compressor power consumption can be calculated.

Table 4: Values of coefficients in the compressor map

\begin{tabular}{|l|l|l|}
\hline$C_{1}=0.9469$ & $C_{8}=0.02698$ & $C_{15}=-5.185$ \\
\hline$C_{2}=1.053$ & $C_{9}=-1.234$ & $C_{16}=5.466$ \\
\hline$C_{3}=161$ & $C_{10}=1.099$ & $C_{17}=42.29$ \\
\hline$C_{4}=68.71$ & $C_{11}=0.003971$ & $C_{18}=-8.066$ \\
\hline$C_{5}=143.4$ & $C_{12}=-4.128 \times 10^{-5}$ & $C_{19}=23.45$ \\
\hline$C_{6}=-28.76$ & $C_{13}=-1.404 \times 10^{-7}$ & $C_{20}=28.71$ \\
\hline$C_{7}=0.8153$ & $C_{14}=0.6863$ & $C_{21}=3352$ \\
\hline
\end{tabular}

A comparison between the experimental data and predicted results for the discharge temperature, mass flow rate and compressor power consumption are shown in Figures 10,11, and 12, respectively. It can be seen that the predicted results agreed well with the experimental results with a mean absolute error (MEA) of $1.44 \mathrm{~K}$ for the discharge temperature, $0.00065449 \mathrm{~kg} / \mathrm{s}$ for the mass flow rate and $34.4 \mathrm{~W}$ for the compressor power consumption. 


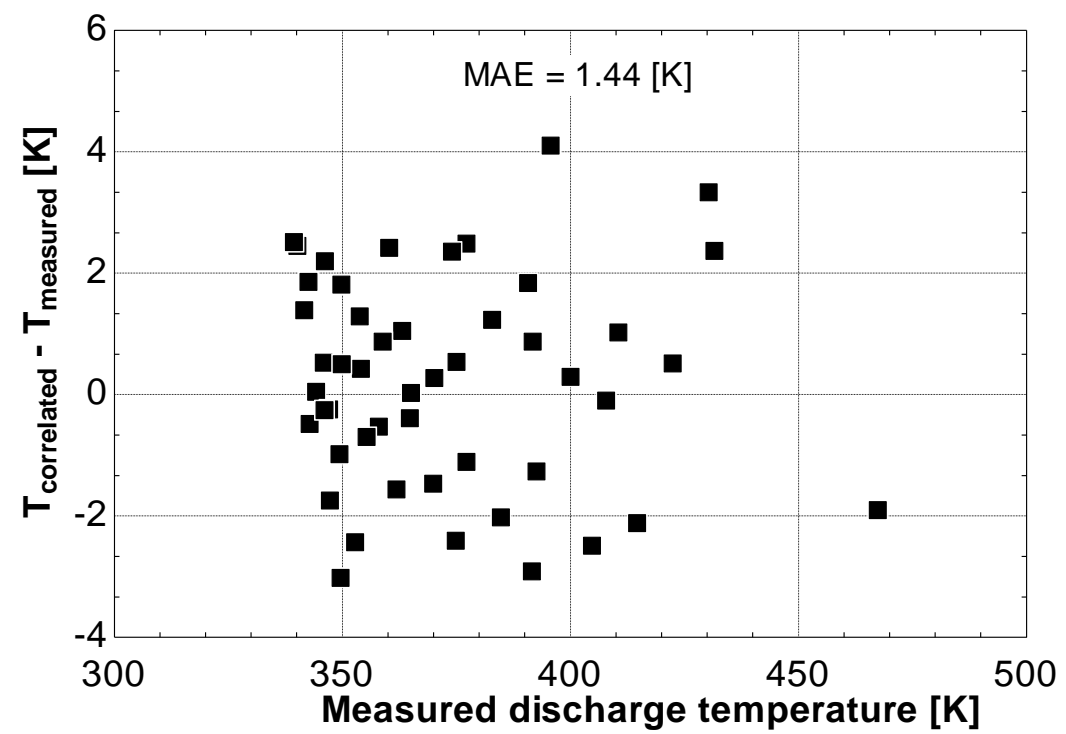

Figure 10. Comparison between measured and correlated discharge temperature

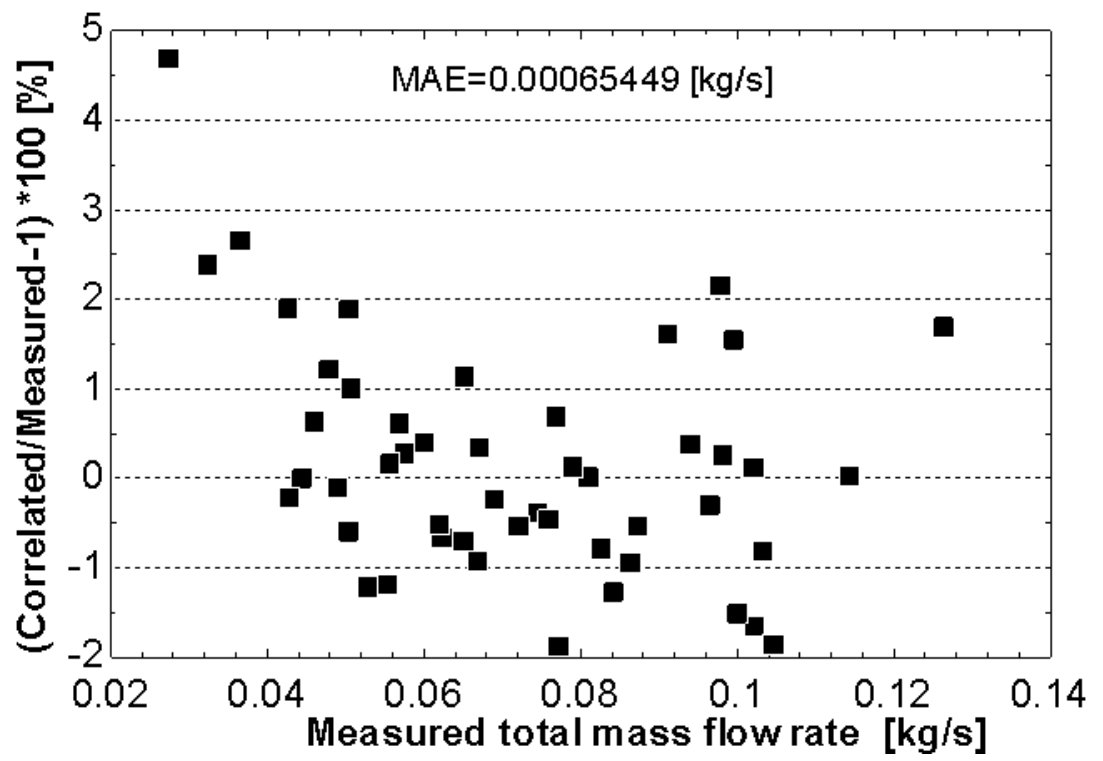

Figure 11. Comparison between measured and correlated total mass flow rate 


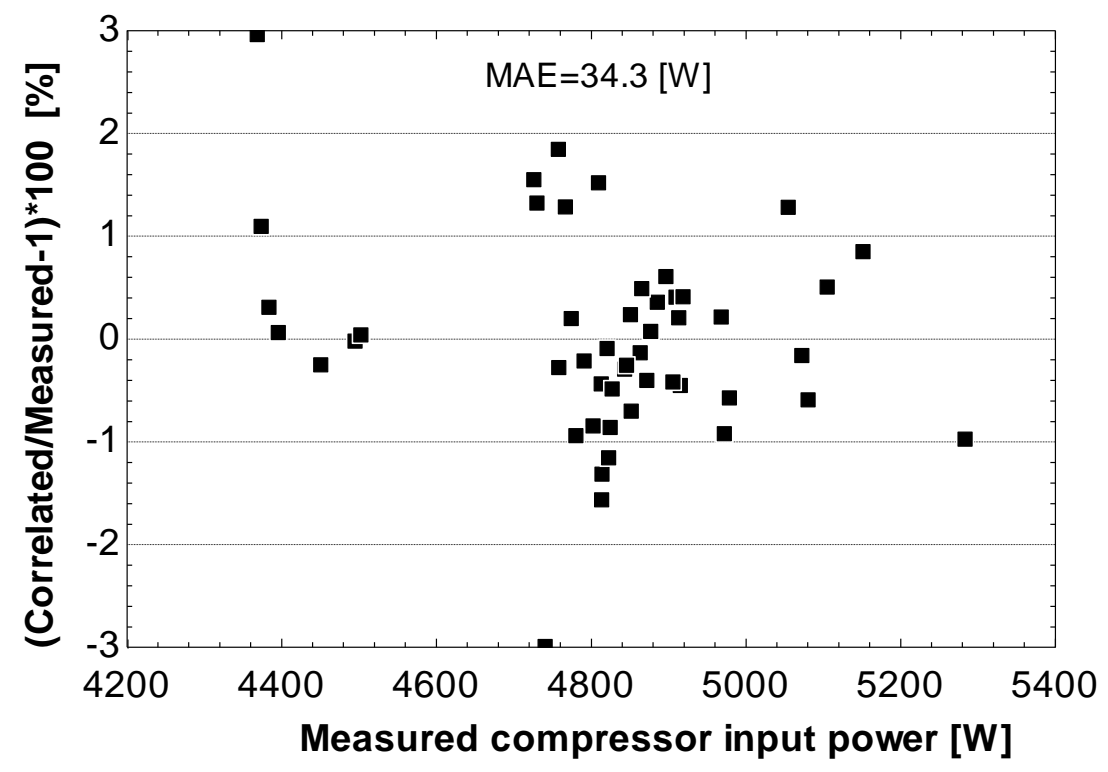

Figure 12. Comparison between measured and correlated compressor input power

\section{Conclusion}

An R410A scroll compressor was tested over a wide range of operating conditions by injecting POE oil into the sealed suction chamber in order to capture the characteristics and performance of the compressor with oil flooding. From the experimental results, it was found that the oil flooded compression results in an increase in refrigerant mass flow rate and a decrease in compressor discharge temperature. While the volumetric efficiency of the compressor steadily increases with oil flooding due to better sealing and reduced leakage, isentropic efficiency has an optimum value at certain oil flow mass fraction due to tradeoffs between reduced leakage and friction and increased pressure drops through suction and discharge pathways. Semi-empirical models were introduced to simulate total mass flow rate and input power consumption of the compressor. The correlation predictions agree well with the experimental results. This compressor map based on experimental testing of POE oil flooded R410A scroll compressor can be used to predict and validate the system behavior of liquid flooded compression with regeneration for various applications.

\section{Acknowledgements}

Financial support for this work was provided by the Department of Energy and Emerson Climate Technologies. The authors would also like to acknowledge Dr. Kirill M. Ignatiev for his useful insights on compressor testing with oil flooding. 


\section{References}

Bell, I., Groll, E. , Braun, J., 2011. Performance of vapor compression systems with compressor oil flooding and regeneration. Int. J. Refrigeration. 34 (1), 225-233.

Bell, I., Groll, E., Braun, J., , Horton, W.T., 2013. Experimental testing of an oil-flooded hermetic scroll compressor. Int. J. Refrigeration. 36 (7), 1866-1873.

Blaise,J., Dutto, T., 1988. Influence of oil injection and pressure ratio on single screw performances at high temperatures. In: 1988 Int. Compress . Eng. Conf. at Purdue University. pp. 338-345.

Cheung, H., Braun, J., 2012. Inverse modeling to simulate fault impacts for vapor compression equipment part 1: component modeling and validation. In 2012 Int. Refrigeration and Air Conditioning Conf. at Purdue University.

Hiwata, A., lida, N.,, Futagami, Y., Sawai, K.Ishii, N., 2002. Performance investigation with oil-injection to compression chambers on $\mathrm{CO}_{2}$-scroll compressor. In: 2002 Int. Compress . Eng. Conf. at Purdue University. \#188-C24.

Hugenroth, J., Braun, J., Groll, E., King, G., 2008. Experimental investigation of a liquid-flooded Ericsson cycle cooler. Int. J. Refrigeration. 31 (7), 1241-1252.

Jahnig, D., Reindl, D., Klein, S., 2000. A semi-empirical method for representing domestic refrigerator/freezer compressor calorimeter test data. ASHRAE Trans. 106 (2), pp. 122-130.

Karnaz, J., CPI Engineering, Midland, MI. August 06, 2012. E-mail conversation with the author.

Kesler, M. G.,Lee, B. I., 1976. Improved prediction of enthalpy of fractions. Hydrocarbon Proc. 55(3), 153-158.

Klein, S.A., 2009. Engineering Equation Solver [computer software], F-Chart Software.

Lemmon, E.,Huber, M., 2007. Refprop 8.0. http://www.nist.gov/srd/nist23.htm.

Sakuda, A., Sawai, K., lida, N., Hiwata, A., Morimoto, T., Ishii, N., 2001. Performance improvement of scroll compressor with new sealing-oil supply mechanism. In 2001: Int. Conf. on Compress. and their Systems. \#C591/019.

Sawai, K., Hiwata, A., Sakuda, A., lida, N., Morimoto, T., Ishii, N., 2009. Experimental study for high efficiency on R410A scroll compressor - 2nd Report: efficiency improvement with new oil injection to compression chambers [Japanese]", Trans. of the JSRAE. 26, 387-395.

Stosic, N., Milutinovic, L., Hanjalic, K., Kovacevic, A. , 1990. Experimental investigation of the influence of oil injection upon the screw compressor working process.In: 1990 Int. Compress . Eng. Conf. at Purdue University.pp. 34-43. 
Appendix: Experimental Data from Testing of Oil Flooded R410A Scroll Compressor

\begin{tabular}{|c|c|c|c|c|c|c|c|c|c|}
\hline S.no. & $\mathrm{T}_{\text {cond }}$ & $T_{\text {evap }}$ & $\Delta \mathrm{T}_{\text {sh }}$ & $\mathrm{T}_{1}$ & $\mathrm{~T}_{11}$ & $x_{\text {oil }}$ & $T_{2}$ & $\dot{m}_{r e f}$ & $\dot{W}_{e l}$ \\
\hline & ${ }^{\circ} \mathrm{C}$ & ${ }^{\circ} \mathrm{C}$ & ${ }^{\circ} \mathrm{C}$ & ${ }^{\circ} \mathrm{C}$ & ${ }^{\circ} \mathrm{C}$ & & ${ }^{\circ} \mathrm{C}$ & $\mathrm{kg} / \mathrm{s}$ & kW \\
\hline 1 & 43.3 & -20 & 15 & -5 & 25 & 0 & 119.40 & 0.0503 & 4.9678 \\
\hline 2 & 43.3 & -20 & 15 & -5 & 25 & 0.1 & 101.87 & 0.0517 & 4.8091 \\
\hline 3 & 43.3 & -20 & 15 & -5 & 25 & 0.2 & 89.96 & 0.0519 & 4.8203 \\
\hline 4 & 43.3 & -20 & 15 & -5 & 25 & 0.3 & 80.64 & 0.0522 & 4.8516 \\
\hline 5 & 43.3 & -20 & 15 & -5 & 25 & 0.4 & 73.01 & 0.0519 & 4.8720 \\
\hline 6 & 43.3 & -20 & 15 & -5 & 25 & 0.5 & 66.96 & 0.0513 & 4.9096 \\
\hline 7 & 43.3 & -20 & 15 & -5 & 25 & 0.51 & 66.20 & 0.0511 & 4.9186 \\
\hline & 122 & 30 & Tr & 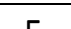 & 25 & 0 & 12151 & 0 & 4001 \\
\hline & $\frac{43.5}{132}$ & 20 & 25 & 5 & 25 & 1 & $101 . J 1$ & $0.04 / 0$ & דיר \\
\hline 2 & 43.3 & -20 & 25 & 5 & 25 & 0.1 & 109.67 & 0.0497 & 4.7574 \\
\hline 3 & 43.3 & -20 & 25 & 5 & 25 & 0.2 & 97.01 & 0.0498 & 4.7743 \\
\hline 4 & 43.3 & -20 & 25 & 5 & 25 & 0.3 & 85.67 & 0.0502 & 4.8130 \\
\hline 5 & 43.3 & -20 & 25 & 5 & 25 & 0.4 & 76.63 & 0.0503 & 4.8432 \\
\hline 6 & 43.3 & -20 & 25 & 5 & 25 & 0.5 & 69.37 & 0.0500 & 4.8852 \\
\hline 7 & 43.3 & -20 & 25 & 5 & 25 & 0.52 & 68.48 & 0.0501 & 4.8962 \\
\hline 1 & 43.3 & -20 & 35 & 15 & 25 & 0 & 141.46 & 0.0459 & 4.9720 \\
\hline 2 & 43.3 & -20 & 35 & 15 & 25 & 0.1 & 118.55 & 0.0474 & 4.7666 \\
\hline 3 & 43.3 & -20 & 35 & 15 & 25 & 0.2 & 104.02 & 0.0481 & 4.7906 \\
\hline 4 & 43.3 & -20 & 35 & 15 & 25 & 0.3 & 91.62 & 0.0483 & 4.8024 \\
\hline 5 & 43.3 & -20 & 35 & 15 & 25 & 0.4 & 80.84 & 0.0486 & 4.8268 \\
\hline 6 & 43.3 & -20 & 35 & 15 & 25 & 0.5 & 72.76 & 0.0483 & 4.8769 \\
\hline 7 & 43.3 & -20 & 35 & 15 & 25 & 0.53 & 71.04 & 0.0483 & 4.9128 \\
\hline 1 & 43.3 & -20 & 45 & 25 & 25 & 0 & 149.24 & 0.0444 & 4.9153 \\
\hline 2 & 43.3 & -20 & 45 & 25 & 25 & 0.1 & 126.87 & 0.0453 & 4.7255 \\
\hline 3 & 43.3 & -20 & 45 & 25 & 25 & 0.2 & 111.54 & 0.0456 & 4.7580 \\
\hline 4 & 43.3 & -20 & 45 & 25 & 25 & 0.3 & 96.74 & 0.0468 & 4.8137 \\
\hline 5 & 43.3 & -20 & 45 & 25 & 25 & 0.4 & 84.78 & 0.0470 & 4.8242 \\
\hline 6 & 43.3 & -20 & 45 & 25 & 25 & 0.5 & 76.20 & 0.0469 & 4.8634 \\
\hline 7 & 43.3 & -20 & 45 & 25 & 25 & 0.535 & 74.04 & 0.0469 & 4.8654 \\
\hline 1 & 43.3 & -20 & 55 & 35 & 25 & 0 & 157.14 & 0.0428 & 4.9057 \\
\hline 2 & 43.3 & -20 & 55 & 35 & 25 & 0.1 & 134.68 & 0.0441 & 4.7298 \\
\hline 3 & 43.3 & -20 & 55 & 35 & 25 & 0.2 & 118.35 & 0.0445 & 4.7800 \\
\hline 4 & 43.3 & -20 & 55 & 35 & 25 & 0.3 & 101.70 & 0.0454 & 4.8131 \\
\hline 5 & 43.3 & -20 & 55 & 35 & 25 & 0.4 & 88.66 & 0.0457 & 4.8223 \\
\hline
\end{tabular}




\begin{tabular}{|l|l|l|l|l|l|l|l|l|l|}
\hline 6 & 43.3 & -20 & 55 & 35 & 25 & 0.5 & 79.59 & 0.0455 & 4.8453 \\
\hline 7 & 43.3 & -20 & 55 & 35 & 25 & 0.54 & 76.46 & 0.0454 & 4.8505 \\
\hline \multicolumn{8}{|c|}{} \\
\hline 1 & 43.3 & -10 & 35 & 25 & 25 & 0 & 122.52 & 0.0668 & 5.2830 \\
\hline 2 & 43.3 & -10 & 35 & 25 & 25 & 0.1 & 104.03 & 0.0693 & 5.0546 \\
\hline 3 & 43.3 & -10 & 35 & 25 & 25 & 0.2 & 91.87 & 0.0695 & 5.0722 \\
\hline 4 & 43.3 & -10 & 35 & 25 & 25 & 0.3 & 82.14 & 0.0685 & 5.0804 \\
\hline 5 & 43.3 & -10 & 35 & 25 & 25 & 0.4 & 73.92 & 0.0685 & 5.1051 \\
\hline 6 & 43.3 & -10 & 35 & 25 & 25 & 0.46 & 69.67 & 0.0686 & 5.1514 \\
\hline \multicolumn{7}{|c|}{} \\
\hline 1 & 43.3 & -20 & 45 & 25 & 25 & 0 & 149.24 & 0.0444 & 4.9153 \\
\hline 2 & 43.3 & -20 & 45 & 25 & 25 & 0.1 & 126.87 & 0.0453 & 4.7255 \\
\hline 3 & 43.3 & -20 & 45 & 25 & 25 & 0.2 & 111.54 & 0.0456 & 4.7580 \\
\hline 4 & 43.3 & -20 & 45 & 25 & 25 & 0.3 & 96.74 & 0.0468 & 4.8137 \\
\hline 5 & 43.3 & -20 & 45 & 25 & 25 & 0.4 & 84.78 & 0.0470 & 4.8242 \\
\hline 6 & 43.3 & -20 & 45 & 25 & 25 & 0.5 & 76.20 & 0.0469 & 4.8634 \\
\hline 7 & 43.3 & -20 & 45 & 25 & 25 & 0.535 & 74.04 & 0.0469 & 4.8654 \\
\hline \multicolumn{8}{|c|}{} \\
\hline 1 & 43.3 & -30 & 55 & 25 & 25 & 0 & 194.18 & 0.0273 & 4.7403 \\
\hline 2 & 43.3 & -30 & 55 & 25 & 25 & 0.1 & 158.43 & 0.0291 & 4.3679 \\
\hline 3 & 43.3 & -30 & 55 & 25 & 25 & 0.2 & 137.34 & 0.0291 & 4.3731 \\
\hline 4 & 43.3 & -30 & 55 & 25 & 25 & 0.3 & 117.55 & 0.0298 & 4.3831 \\
\hline 5 & 43.3 & -30 & 55 & 25 & 25 & 0.4 & 100.85 & 0.0303 & 4.3954 \\
\hline 6 & 43.3 & -30 & 55 & 25 & 25 & 0.5 & 87.07 & 0.0308 & 4.4500 \\
\hline 7 & 43.3 & -30 & 55 & 25 & 25 & 0.6 & 76.67 & 0.0305 & 4.4945 \\
\hline 8 & 43.3 & -30 & 55 & 25 & 25 & 0.64 & 72.91 & 0.0300 & 4.5022 \\
\hline
\end{tabular}

